\title{
Performance Analysis of Current Source Inverter Fed Induction Motor Drive with Direct Torque Control
}

\author{
R.Chidanandappa ${ }^{1}$, Dr.T.Ananthapamnabha ${ }^{2}$ \\ Assistant professor, Dept. of EEE, The National Institute of Engineering, Mysore, Karnataka, India ${ }^{1}$ \\ Professor, Dept. of EEE, The National Institute of Engineering, Mysore, Karnataka, India ${ }^{2}$
}

\begin{abstract}
Current Source Inverter (CSI) fed induction motor drives finds application in high power medium voltage drives such as fan drives, where fast dynamic response is not needed because of the inherent four quadrant operation and reliability. Speed control of induction motors by Direct Torque Control -DTC method has more advantages compared to other methods. The most important Constant - Switching of DTC with PI control method based on constant switching frequency with modification of the inverter optimal switching table is presented. By using Direct torque control method the torque and speed response can be improved and thus improving the performance of the machine. The Matlab/Simulink software is used to model the CSI fed induction motor drive with DTC control and performance parameter are analysed and compared.
\end{abstract}

KEYWORDS: current source converter, Direct torque control, space-vector modulation (SVM)

\section{INTRODUCTION}

The direct torque control (DTC) is one of the actively researched control schemes of induction machines, that provides a very quick and precise torque response without the complex field-orientation block and the inner current regulation loop. In Direct Torque Control it is possible to control directly the stator flux and the torque by selecting the appropriate inverter state.. DTC is the latest AC motor control method, developed with the goal of combining the implementation of the V/f-based induction motor drives with the performance of those based on vector control [1-3]. It is not intended to vary amplitude and frequency of voltage supply or to emulate a DC motor, but to exploit the flux and torque producing capabilities of an induction motor when fed by an inverter .CSI permits easy power regeneration to the supply network under the breaking conditions, what is favorable in large power induction motor drives. In a direct torque controlled induction motor drive supplied by current source inverter it is possible to control directly the modulus of the rotor flux-linkage space vector through the rectifier voltage, and the electromagnetic torque by the supply frequency of the CSI[4]. In this paper the solution based on a stator flux vector control (SFVC) scheme has been proposed. This scheme may be considered as a development of the basic DTC scheme with the aim of improving the drive performance.

\section{CONSTANT SWITCHING DIRECT TORQUE CONTROL}

In DTC schemes, the presence of hysteresis controllers for flux and torque determines variable-switching-frequency operation for the inverter. Furthermore, using DTC schemes an fast torque response over a wide speed range can be achieved only using different switching tables at low and high speed. The problem of variable switching frequency can be overcome by different methods [5]. Controllers based on direct torque control do not require a complex coordinate transform. The decoupling of the nonlinear ac motor structure is obtained by the use of on-off control, which can be related to the on-off operation of the inverter power switches. Similarly to direct vector control, the flux and the torque are either measured or estimated and used as feedback signals for the controller. However, as opposed to vector control, the states of the power switches are determined directly by the measured and the reference torque and flux signals. This is achieved by means of a switching table, the inputs of which are the torque error, the stator flux error and the stator flux angle quantized into six sections. The outputs of the switching table are the settings for the switching 


\section{International Journal of Advanced Research in Electrical, Electronics and Instrumentation Engineering}

\section{(An ISO 3297: 2007 Certified Organization)}

Vol. 3, Issue 9, September 2014

devices of the inverter. In proposed stator flux vector control (SFVC), the input commands are the torque and the rotor flux, whereas the control variables are the stator flux components. The principle of operation is based on driving the stator flux vector toward the corresponding reference vector defined by the input commands. This action is carried out by the space-vector modulation (SVM) technique, which applies a suitable voltage vector to the machine in order to compensate the stator flux vector error. In this way it is possible to operate the induction motor drive with a constant switching frequency.

The proposed DTC-CSI drive shown in Fig.1. the inputs are rotor flux and torque but the stator flux angle $\alpha_{\mathrm{s}}$ is a control
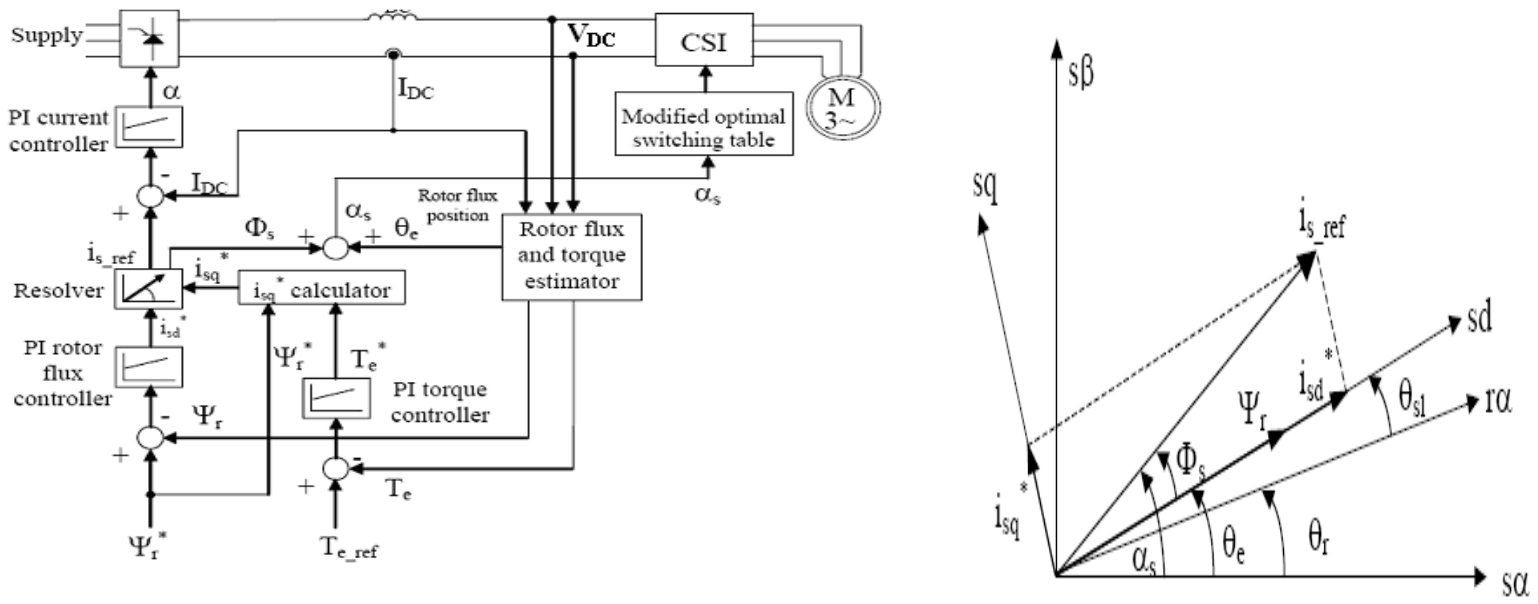

Fig 1. Constant-switching DTC strategy in CSI fed induction motor drive

Fig 2. Position of stator current and rotor flux vectors.

Identical result would be obtained when phase angle $\Phi_{\mathrm{s}}$ between $d-q$ current references and rotor flux vector angle $\theta \mathrm{e}=\arctan (\operatorname{\Psi r} \beta / \Psi \mathrm{r} \alpha)$ are summed and resulting angle $\alpha_{s}$ is then used to determine sector of 60 degrees where resides rotor flux vector. In that way, phase angle $\Phi$ s acts as a torque control command, since when reference torque is changed, $i_{s q} *$ is momentary changed . Fig. 2. represent phasor diagram with reference current vector, rotor flux vector and corresponding angles.

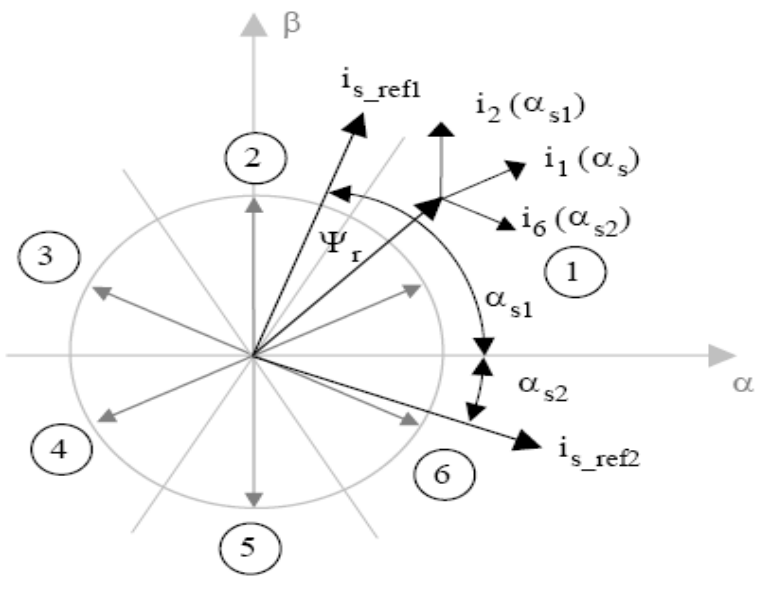

Fig 3 Selecting proper current vector in proposed DTC algorithm
Table 1. Optimal switching table in DTC

\begin{tabular}{|c|l|}
\hline $\begin{array}{c}\text { Current } \\
\text { Vector }\end{array}$ & \multicolumn{1}{c|}{ Angle Range } \\
\hline$i_{1}$ & $0^{\circ}<{ }_{\mathrm{s}} \leq 60^{\circ}$ \\
\hline$i_{2}$ & $60^{\circ}<{ }_{\mathrm{s}_{\mathrm{s}}} \leq 120^{\circ}$ \\
\hline$i_{3}$ & $120^{\circ}<{ }_{\mathrm{s}} \leq 180^{\circ}$ \\
\hline$i_{4}$ & $180^{\circ}<{ }_{\mathrm{s}} \leq 240^{\circ}$ \\
\hline$i_{5}$ & $240^{\circ}<{ }_{\mathrm{s}} \leq 300^{\circ}$ \\
\hline$i_{6}$ & $300^{\circ}<{ }_{\mathrm{s}} \leq 360^{\circ}$ \\
\hline
\end{tabular}




\title{
International Journal of Advanced Research in Electrical, Electronics and Instrumentation Engineering
}

\author{
(An ISO 3297: 2007 Certified Organization)
}

Vol. 3, Issue 9, September 2014

Phase angle $\Phi_{\mathrm{s}}$ "moves" stator current vector $i_{s}$ in direction determined by the sign of torque reference and its value accelerate or decelerate flux vector movement according to the value of the reference torque (Fig.3). This modification implies somewhere different switching table for activating inverter switches, as shown in Table 1 , where $\alpha_{\mathrm{s}}$ is angle between reference $\alpha$-axis and reference current vector $i_{s}$. That angle determines which current vector should be chosen: $i_{2}$ for torque increase, $i_{6}$ for torque decrease or $i_{1}$ for keeping torque at the current value.

\section{MEASURING AND ESTIMATION}

The stator flux value, needed for DTC control loop, is not convenient to measure directly. Instead of that, the motor flux estimation is done. In the voltage-based estimation method, the motor flux can be obtained by integrating its back electromotive force (EMF). The EMF is calculated from the motor voltage and current and the only motor parameter required is the stator winding resistance. The input variables of the proposed prototype are motor torque $T_{e}^{*}$ and rotor flux amplitude $\Psi_{r}^{*}$. Control variables are current components in synchronous reference frame $i_{s d}^{*}$ and $i_{s q}^{*}$ and phase angle between them $\left(\Phi_{s}\right)$. D-axis component $i_{s d} *$ is determined as the output of the PI rotor flux controller, while q-axis component $i *$ is calculated from the input variables and motor.

$i_{s q}^{*}=\left(2 . L_{r} . T_{e} *\right) /\left(3 . p . L_{m} . \Psi_{r}^{*}\right)$

where $L_{r}$ is rotor inductance, $L_{m}$ is mutual inductance and $p$ denotes pair of poles.

Phase angle $\Phi$ and rectifier reference current are obtained as a result of rectangular to polar coordinate transformation

$$
\begin{aligned}
& \Phi_{s}=\arctan \left(i_{s q} * / i_{s d} *\right) \\
& \mathrm{i}_{\text {ref }}=\sqrt{\left(\mathrm{i}_{s q} *\right)^{2}+\left(\mathrm{i}_{\text {sd }} *\right)^{2}}
\end{aligned}
$$

The induction machine stator and rotor flux equations in terms of space vectors, written in a synchronous reference

frame are $\quad \Psi *=L_{s} . i_{s}+L_{m} . i_{r}$

$$
\stackrel{s}{\Psi} *=L_{r} . i_{r}+L_{m} . i_{s}
$$

Substituting $i_{r}$ in (4) and (5) the reference value of the stator flux vector in synchronous frame is determined, knowing the reference rotor flux and reference stator current:

$$
\Psi_{s}^{*}=\left(L_{m} / L_{r}\right) / . \Psi_{r}^{*}+\left(\left(L_{s .} L_{s}-L_{m}{ }^{2}\right) / L_{r}\right) . i_{s}^{*}
$$

Since flux estimator operates in stationary reference frame, after coordinate transformation (3.6) become:

$$
\Psi_{s \alpha \beta} *=\left(L_{m} / L_{r}\right) / . \Psi_{r \alpha \beta}^{*}+\left(\left(L_{s .} L_{s}-L_{m}{ }^{2}\right) / L_{r}\right) . i_{s \alpha \beta} *
$$

Where

$$
\begin{aligned}
& {\left[\begin{array}{l}
\Psi_{r \alpha} * \\
\Psi_{r \beta} *
\end{array}\right]=\left[\begin{array}{cc}
\cos \theta_{e} & -\sin \theta_{e} \\
\sin \theta_{e} & \cos \theta
\end{array}\right]\left[\begin{array}{c}
\psi_{r} * \\
0
\end{array}\right]} \\
& {\left[\begin{array}{c}
i^{*}{ }_{s \alpha} \\
i^{*}{ }_{s \beta}
\end{array}\right]=\left[\begin{array}{cc}
\cos \theta_{e} & -\sin \theta_{e} \\
\sin \theta_{e} & \cos \theta
\end{array}\right]\left[\begin{array}{c}
i^{*}{ }_{s d} \\
i^{*}{ }_{s q}
\end{array}\right]}
\end{aligned}
$$

and $\theta_{\mathrm{e}}$ is rotor flux angle, $i_{s d} *$ is output of rotor flux controller and $i_{s q} *$ is given in (1).

The voltage and the current of CSI fed induction motor, necessary for stator flux calculation, can be reconstructed from the DC link quantities knowing the states of the conducting inverter switches [11].The main feedback signals in DTC control method are the estimated flux and torque. They are obtained as outputs of the estimator operating in stator reference frame. This estimator at first performs electro-motive force (EMF) integration to determine the stator

flux vector: $\quad \Psi_{s}^{s}=\int_{0}^{t}\left(V_{s}^{s}-R_{S} \cdot \vec{i}_{s}{ }^{s}\right) d t+\Psi_{s 0}{ }^{s}$ 


\title{
International Journal of Advanced Research in Electrical, Electronics and Instrumentation Engineering
}

\author{
(An ISO 3297: 2007 Certified Organization)
}

Vol. 3, Issue 9, September 2014

and then calculates the flux amplitude and find the sector of 60 degrees in $\alpha-\beta$ plane where flux vector resides, according to the partition shown in Fig. 3. The trajectory of flux vector is not circular in the presence of DC offset. Since its undisturbed radius equals $\Psi_{\mathrm{s}}^{*}$, the offset components tend to drive the entire trajectory toward one of the $\pm \Psi_{\mathrm{s}}^{*}$ boundaries.

A contribution to the EMF offset vector can be estimated from the displacement of the flux trajectory as: $e m f_{\alpha \beta}^{\text {off }}=(1 / \Delta t) \cdot\left(\Psi_{\alpha \beta \max }+\Psi_{\alpha \beta \min }\right)$

where the maximum and minimum values in (9) are those of the respective components $\Psi_{\mathrm{s} \alpha}$ and $\Psi_{\mathrm{s} \beta}$, and $\Delta \mathrm{t}$ is the time difference that defines a fundamental period. The estimated rotor flux is calculated from the stator flux estimate using motor parameters and reconstructed stator current:

$\Psi_{r \alpha \beta}=\left(L_{r} / L_{m}\right) / . \Psi_{s \alpha \beta}-\left(\left(L_{s .} L_{r}-L_{m}^{2}\right) / L_{m}\right) \cdot i_{s \alpha \beta}$

and its position in $\alpha-\beta$ reference frame is determined by:

$\theta_{e}=\arctan \left(\Psi_{r \beta} / \Psi_{r \alpha}\right)$

(11)

Finally, from the estimated stator flux and reconstructed current vector the motor torque is given by $T_{e}=(3 / 2) \cdot p \cdot\left(i_{s \beta} \Psi_{s \alpha}-i_{s \alpha} \Psi_{s \beta}\right)$

where the stator flux and current vectors are given in stationary $\alpha-\beta$ frame, and p denotes the number of poles.

\section{MODELING OF CURRENT SOURCE INVERTER}

In current source inverter (CSI), the input behaves as a current source, the output current is maintained constant irrespective of the load on the inverter and the output voltage is forced to change. The circuit diagram of three phase current source inverter is shown in Fig 4.A three phase output can be obtained from a configuration of six switches Two types of control signals can be applied to the switch: $180^{\circ}$ and $120^{\circ}$ conduction. The $180^{\circ}$ conduction has better utilization of switches and is the preferred method.

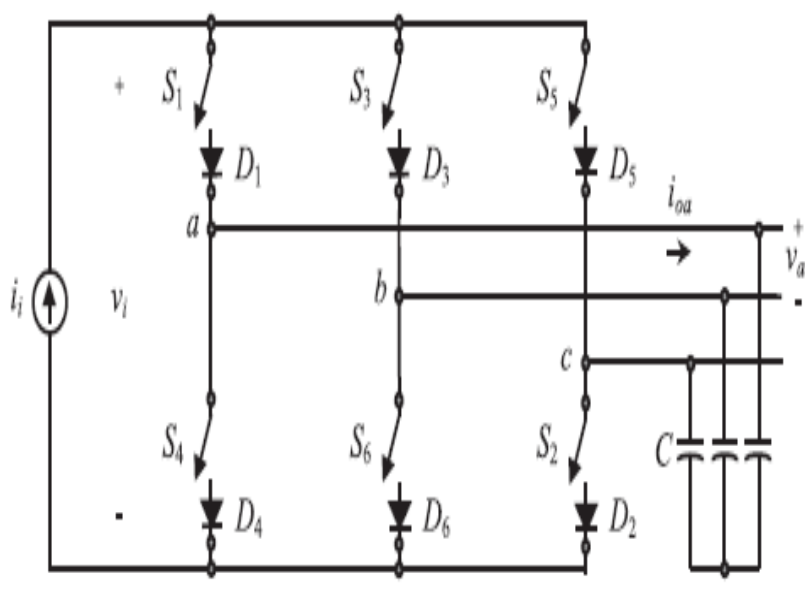

Fig. 4 Three-phase current source inverter

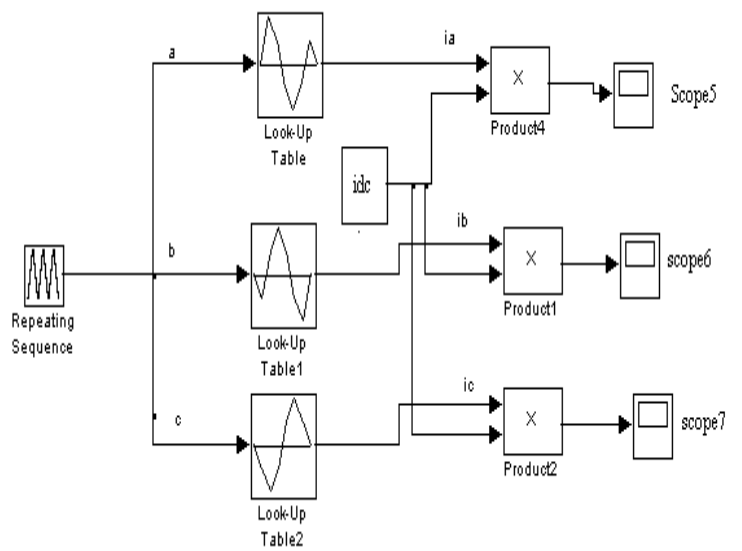

Fig.5.simulink model of CSI

Each switch conducts for $180^{\circ}$. When switch $\mathrm{S}_{1}$ is ON then terminal a is connected to the positive terminal of the DC input voltage. When switch $\mathrm{S}_{4}$ is $\mathrm{ON}$ terminal a is brought to the negative terminal of the DC source. The table 2. shows six valid switching states . 


\section{International Journal of Advanced Research in Electrical, Electronics and Instrumentation Engineering}

(An ISO 3297: 2007 Certified Organization)

Vol. 3, Issue 9, September 2014

Table .2 Switching States of current source inverter.

\begin{tabular}{|c|c|c|c|c|c|}
\hline State & Switching States & State no. & $\mathrm{I}_{\mathrm{a}}$ & $\mathrm{I}_{\mathrm{b}}$ & $\mathrm{I}_{\mathrm{c}}$ \\
\hline $\mathrm{S}_{4}, \mathrm{~S}_{6}$ and $\mathrm{S}_{2}$ are ON & 000 & 1 & 0 & 0 & 0 \\
\hline $\mathrm{S}_{6}, \mathrm{~S}_{2}$ and $\mathrm{S}_{1}$ are ON & 100 & 2 & 1 & -0.5 & 0.5 \\
\hline $\mathrm{S}_{2}, \mathrm{~S}_{3}$ and $\mathrm{S}_{1}$ are ON & 110 & 3 & 0.5 & 0.5 & -1 \\
\hline $\mathrm{S}_{3}, \mathrm{~S}_{4}$ and $\mathrm{S}_{2}$ are ON & 010 & 4 & -0.5 & 1 & -0.5 \\
\hline $\mathrm{S}_{4}, \mathrm{~S}_{5}$ and $\mathrm{S}_{3}$ are ON & 011 & 5 & -1 & 0.5 & 0.5 \\
\hline $\mathrm{S}_{5}, \mathrm{~S}_{6}$ and $\mathrm{S}_{4}$ are ON & 001 & 6 & -0.5 & -0.5 & 1 \\
\hline $\mathrm{S}_{6}, \mathrm{~S}_{1}$ and $\mathrm{S}_{5}$ are ON & 101 & 7 & 0.5 & -1 & 0.5 \\
\hline $\mathrm{S}_{1}, \mathrm{~S}_{3}$ and $\mathrm{S}_{5}$ are ON & 111 & 8 & 0 & 0 & 0 \\
\hline
\end{tabular}

The current source inverter converts direct current into alternating current. Fig .5 shows the simulink model of CSI. The look up table is designed to suit the switching state of current source inverter given in Table 2.

\section{RESULTS AND DISCUSSIONS}

The block diagram of proposed work is given in fig 6 . It consists of rectifier bridge, current source inverter(CSI), Induction motor, control circuit and capacitor bank. Rectifier bridge converts the AC input from source to DC. Current source inverter converts the DC input to AC output which consists of harmonics. The output of CSI is filtered using capacitor and fed to the induction motor. The control circuit block simulates the Direct torque control algorithm .

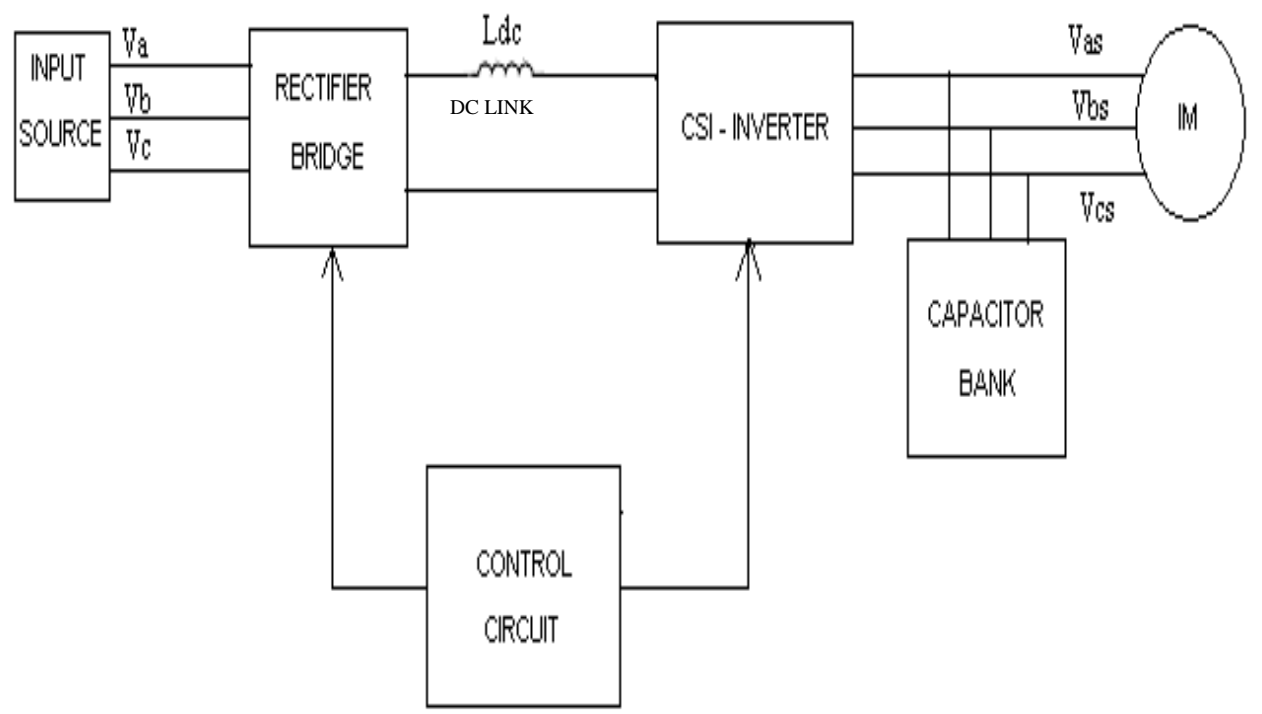

Fig. 6. Basic block diagram of DTC control of high power CSI fed induction motor drive

The parameter values used in modeling are Induction motor of $400 \mathrm{~V}, 3.78 \mathrm{KW}, 50 \mathrm{HZ}, \mathrm{R}_{\mathrm{s}}=\mathrm{R}_{\mathrm{r}}=1.5313 \Omega$, $\mathrm{L}_{\mathrm{s}}=\mathrm{L}_{\mathrm{r}}=0.2194 \mathrm{H}, \mathrm{L}_{0}=0.21 \mathrm{H}$, Poles $=4$, Flux rated $=1.555 \mathrm{wb}, \mathrm{J}=0.25 \mathrm{Kg} \_\mathrm{m}^{2}, \mathrm{~B}=0.0248 \mathrm{Kg} \mathrm{m}_{-}^{2} / \mathrm{sec}$, $\mathrm{Ldc}=42 \mathrm{mH}, \mathrm{Cdc}=11 \mu \mathrm{F}$.

Each block is modeled in Matlab/ simulink software, the simulation model of the block diagram shown in fig7. The Simulation carried out for fallowing cases ;

1. CSI fed induction motor drive without DTC control

2. CSI fed induction motor drive with DTC control 


\section{International Journal of Advanced Research in Electrical, Electronics and Instrumentation Engineering}

(An ISO 3297: 2007 Certified Organization)

Vol. 3, Issue 9, September 2014

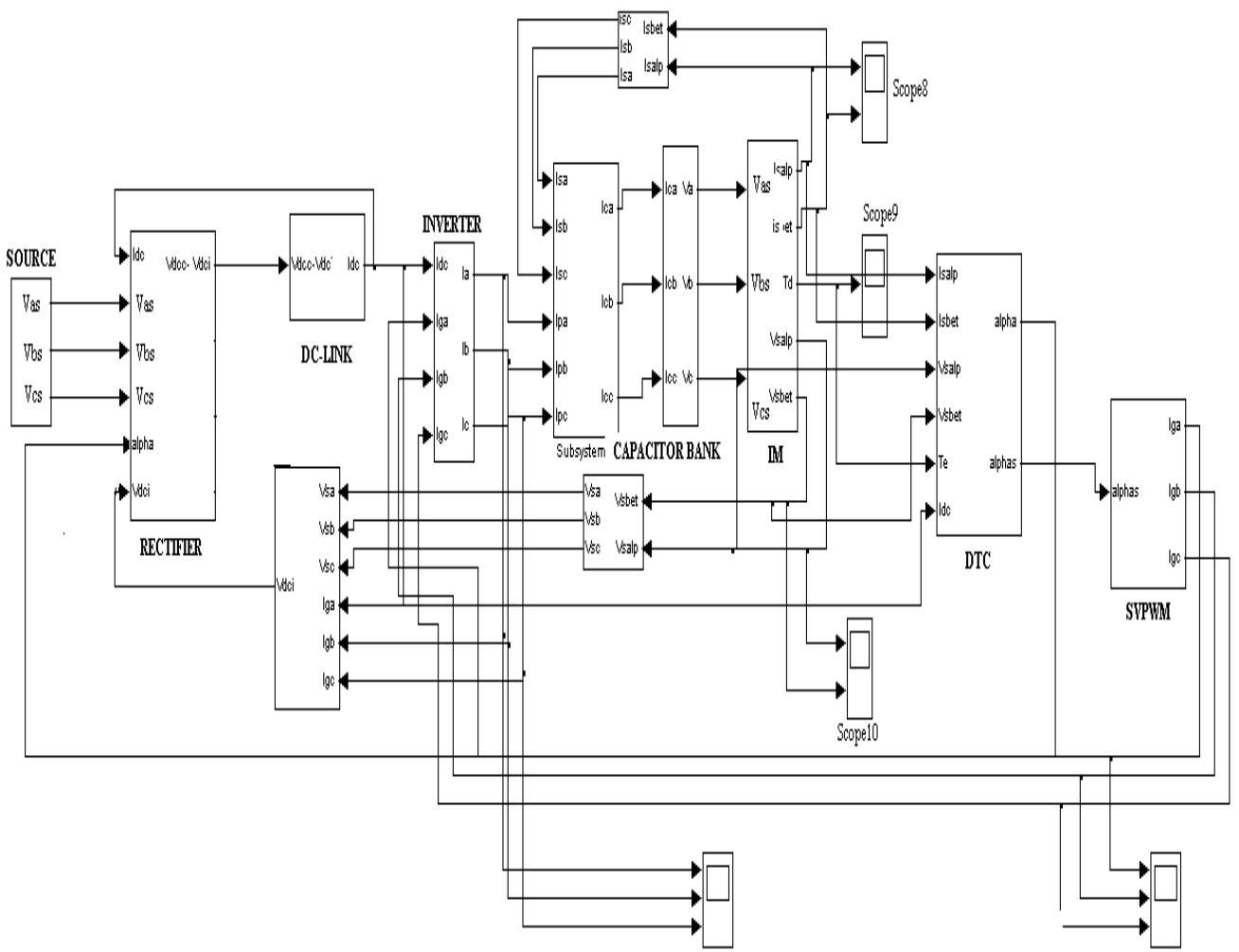

Fig.7. Simulation model of the block diagram of CSI fed induction motor drive

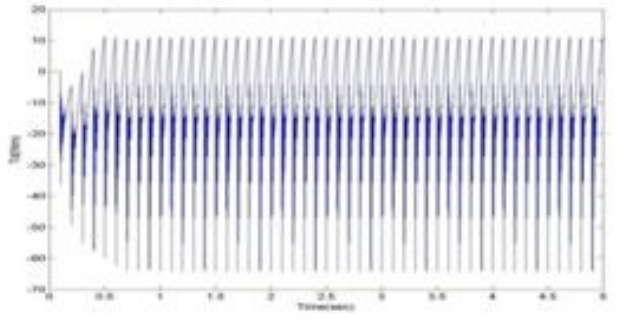

(a)

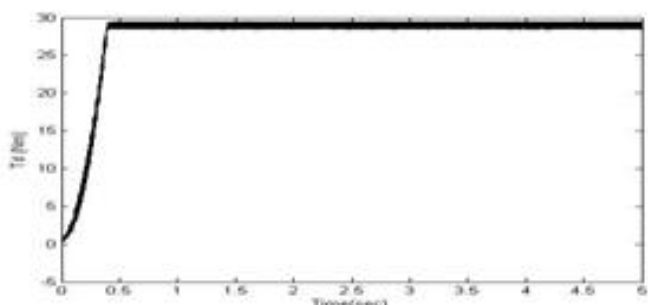

(b)

Fig.8. Torque wave fom of an induction motor without and with DTC

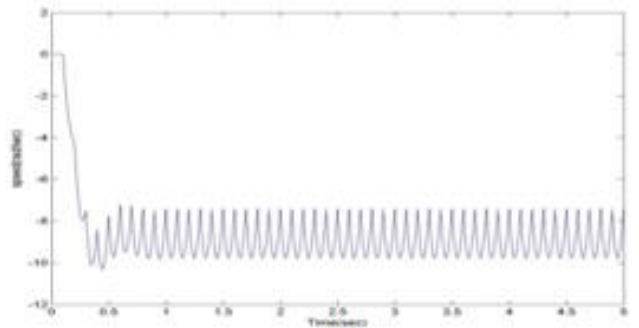

(a)

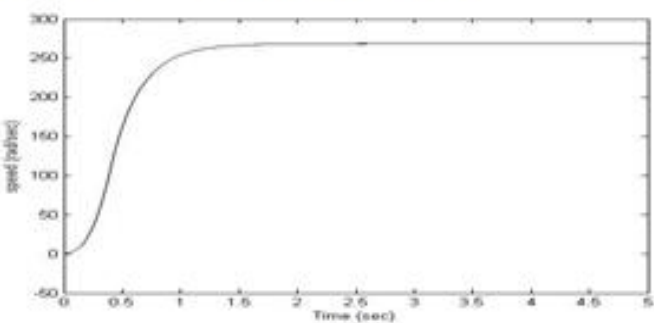

(b)

Fig. 9. Speed wave form of an induction motor without and with DTC 


\section{International Journal of Advanced Research in Electrical, Electronics and Instrumentation Engineering}

(An ISO 3297: 2007 Certified Organization)

Vol. 3, Issue 9, September 2014
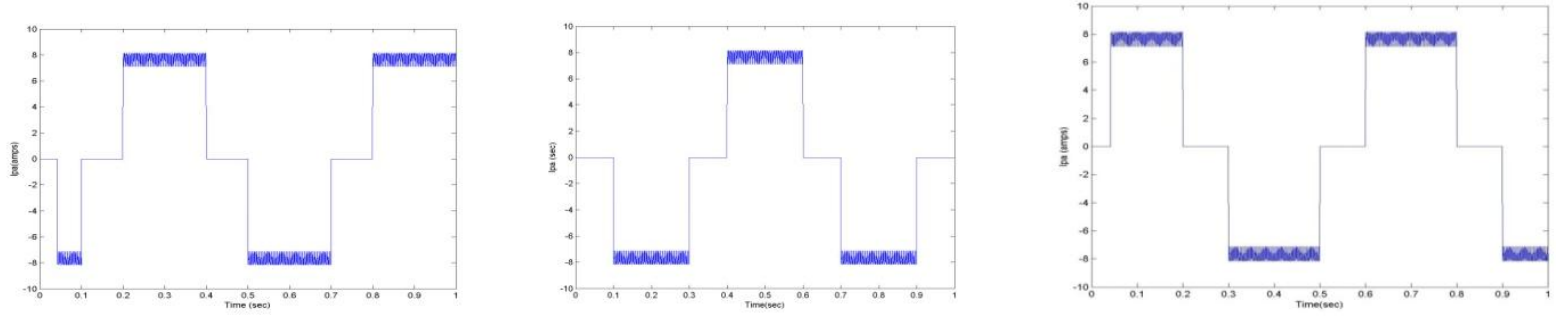

Fig 10. CSI output phase currents without DTC
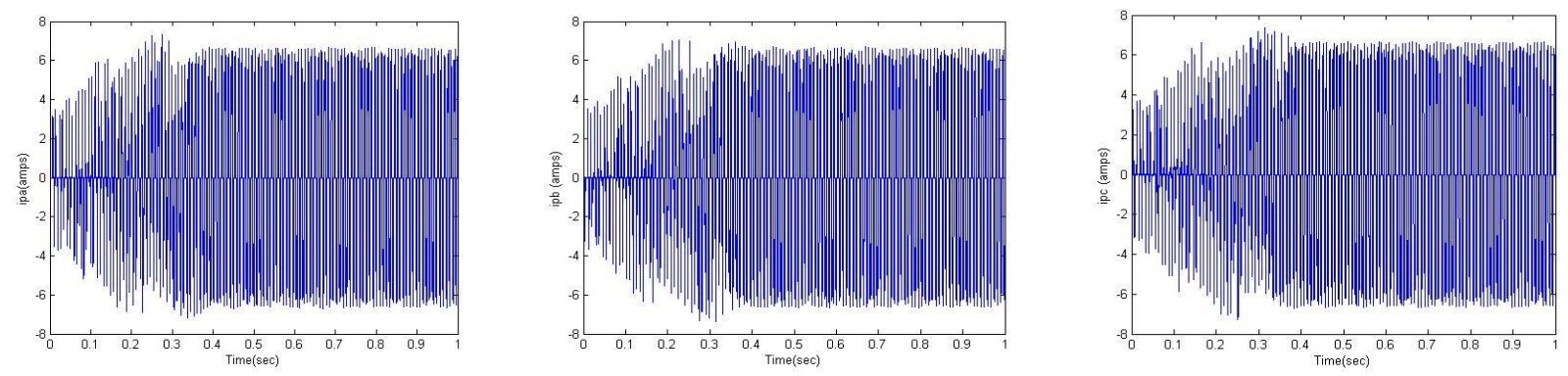

Fig 11. CSI output currents with DTC

From the simulation results shown in fig 8 (a) an 9(a) without DTC control, the torque and speed response is slow and consists of ripple due to harmonics produced by CSI. The induction motor torque and speed response is fast with Direct Torque control method and stability is attained quickly at $0.4 \mathrm{sec}$ as seen from fig 8(b) and fig. 9(b). Without DTC , CSI output current in all phases contains more ripple shown in fig .10 and ripples are reduced with DTC shown in fig 11 .
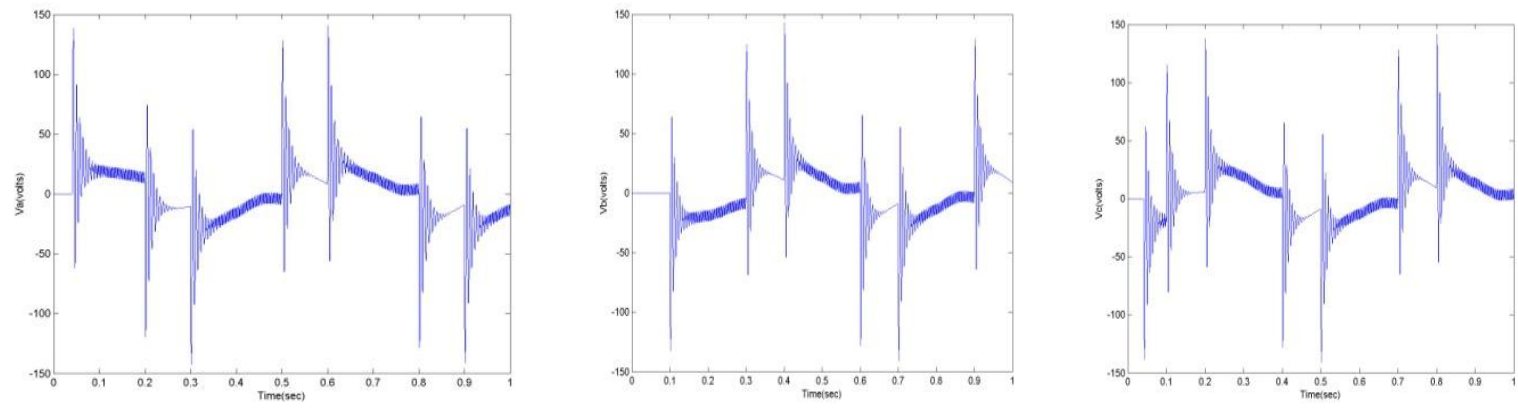

Fig 12. Stator input phase currents of induction motor without DTC
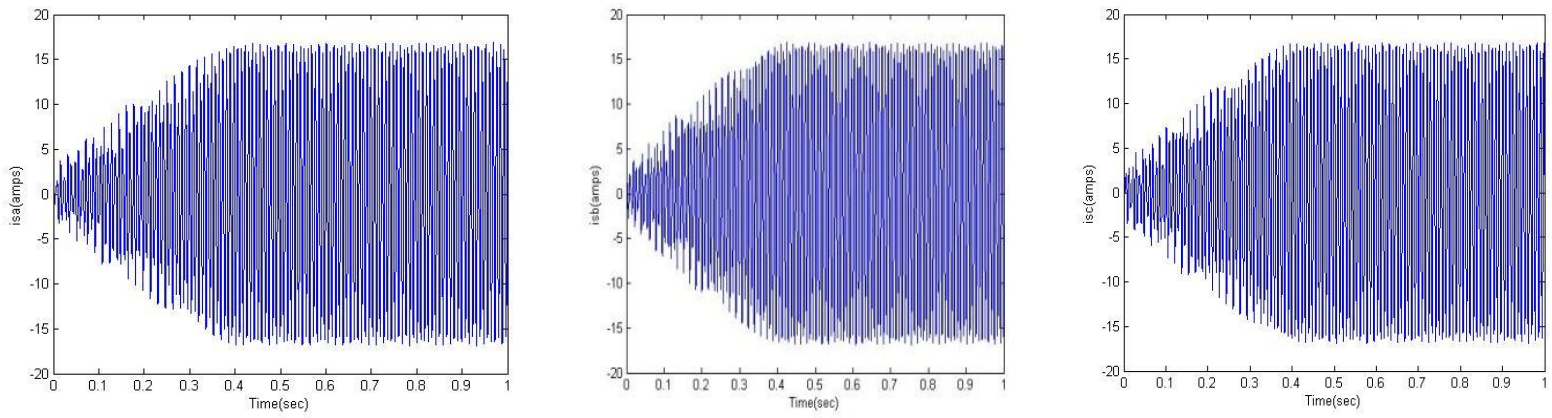

Fig .13. Stator input phase currents of induction motor with DTC 


\section{International Journal of Advanced Research in Electrical, Electronics and Instrumentation Engineering}

(An ISO 3297: 2007 Certified Organization)

Vol. 3, Issue 9, September 2014
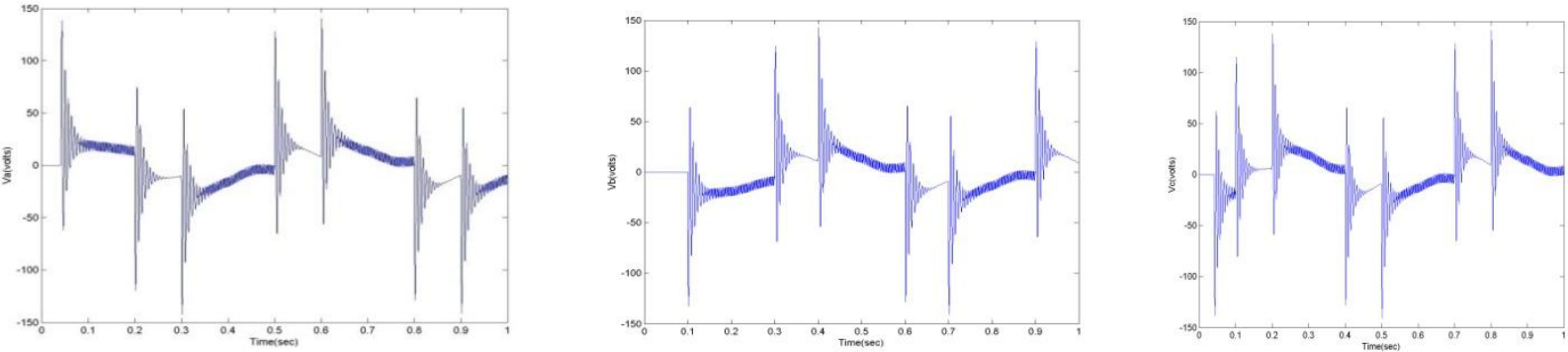

Fig .14. Induction motor input phase voltage without DTC
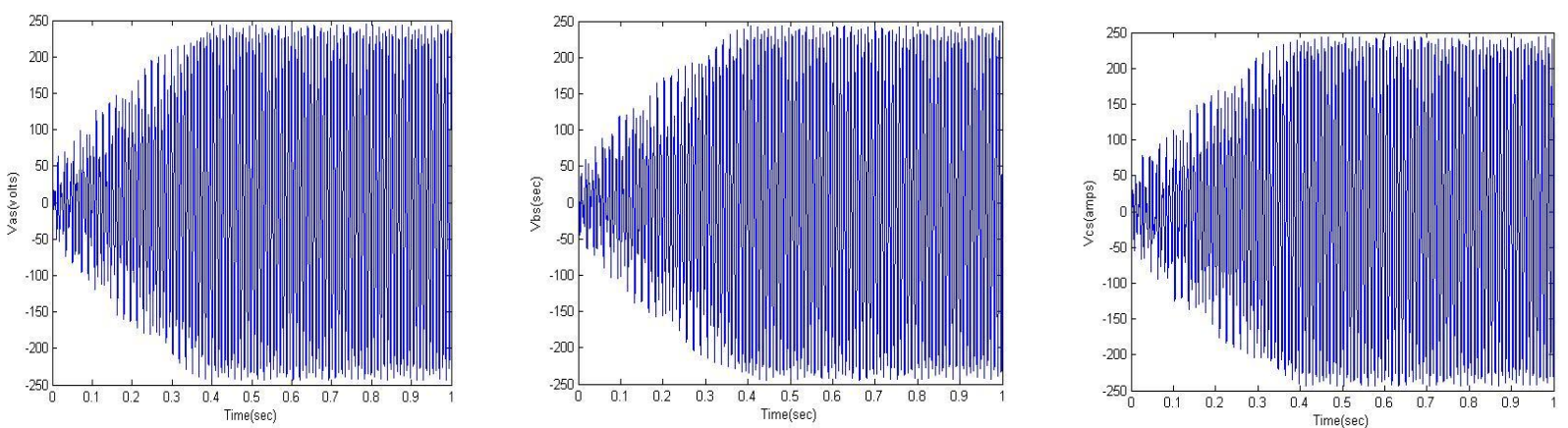

Fig .15. Induction motor input phase voltage with DTC

The stator input currents and input voltages obtained without DTC control, are not reached to nominal values and contains harmonics shown in fig 12 and fig 14 respectively. From the in fig.13 and fig.15 it is seen that ,with DTC control induction motor phase currents and voltages reached to desired operating value and approximately sinusoidal in nature .
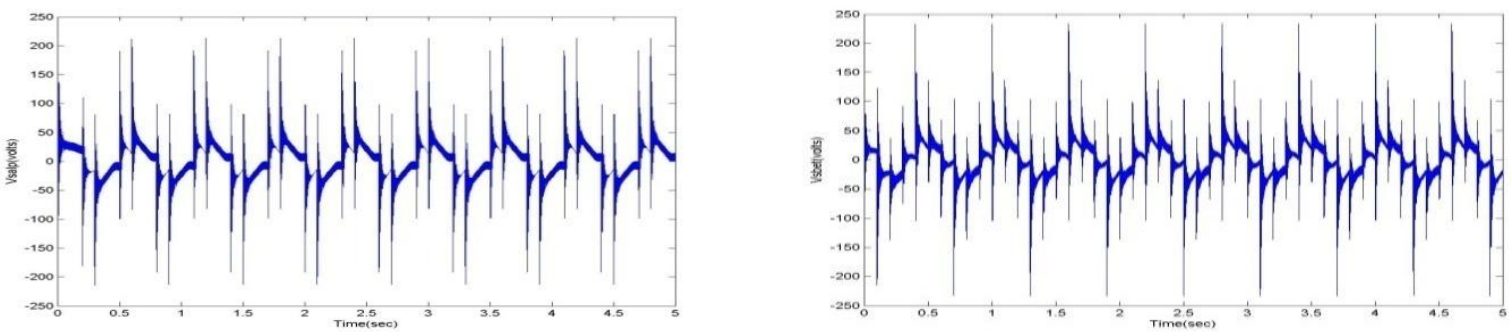

Fig.16 Alpha- Beta stator voltages of an induction motor without DTC
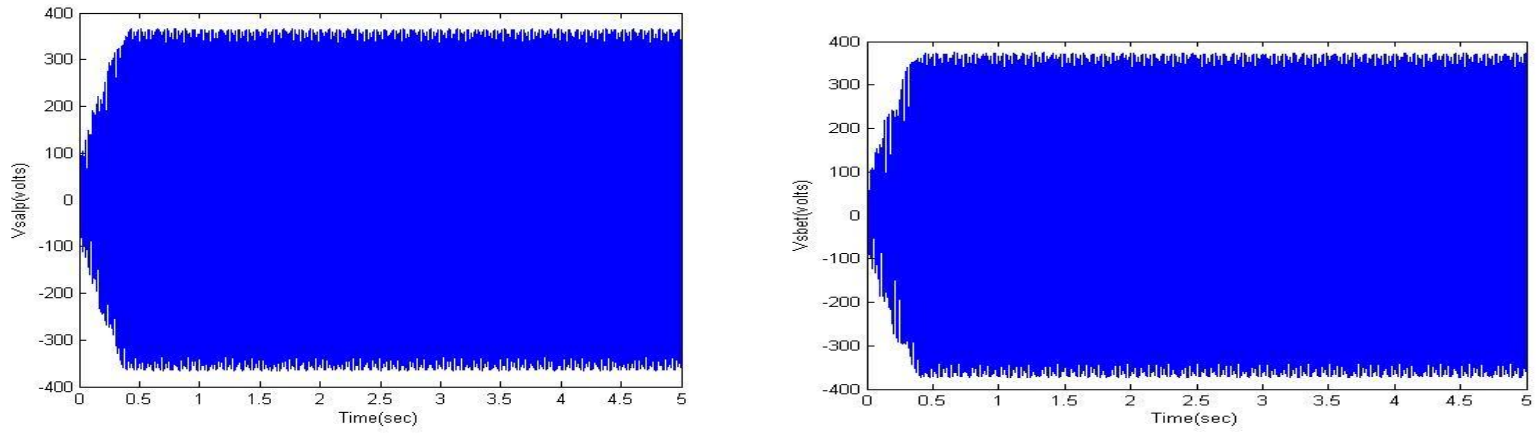

Fig.19 Alpha- Beta stator voltages of an induction motor with DTC 


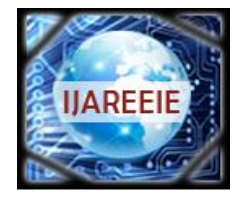

\title{
International Journal of Advanced Research in Electrical, Electronics and Instrumentation Engineering
}

\author{
(An ISO 3297: 2007 Certified Organization)
}

\section{Vol. 3, Issue 9, September 2014}

The Stator currents and voltages in alpha-beta reference frame are almost sinusoidal and stator current attains stability fast as seen from the fig16 and fig 17 respectively. DTC indirectly controls stator current and voltage, reducing Vsalpa, Vsbeta to $375 \mathrm{~V}$ as seen from fig 17. Depending on which sector does the rotor flux falls, particular inverter gate pulses are selected.The rotor flux estimated is sinusoidal and it has circular trajectory as seen from fig 18. From the simulation of the two cases, performance parameters of drive with and without DTC scheme are compared and tabulated in table 3 .

Table 3. performance analysis of CSI fed Induction motor drive without and with DTC scheme

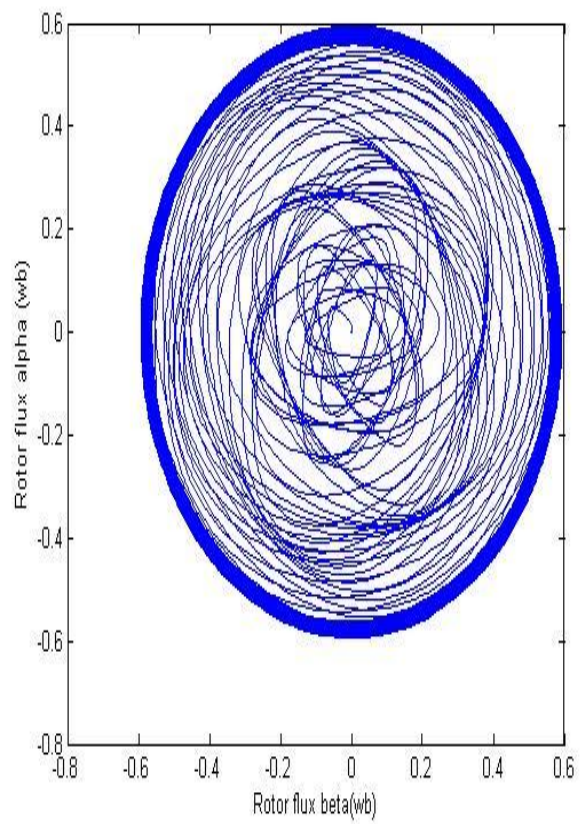

Fig .18 Circular trajectory of Rotor flux

\begin{tabular}{|l|l|l|}
\hline \multicolumn{1}{|c|}{$\begin{array}{c}\text { Performance } \\
\text { Parameter }\end{array}$} & $\begin{array}{l}\text { CSI fed Induction } \\
\text { motor drive without } \\
\text { DTC }\end{array}$ & $\begin{array}{l}\text { CSI fed Induction } \\
\text { motor drive with } \\
\text { DTC }\end{array}$ \\
\hline 1.CSI Output currents & Consists of ripple & $\begin{array}{l}\text { Consists of less } \\
\text { ripple }\end{array}$ \\
\hline 2. Capacitor currents & Consists of ripple & $\begin{array}{l}\text { Approxomate sine } \\
\text { wave }\end{array}$ \\
\hline 3.Stator input voltages & Not sine wave & $\begin{array}{l}\text { Approxomate sine } \\
\text { wave }\end{array}$ \\
\hline $\begin{array}{l}\text { 4. Stator input currents } \\
\text { Not sine wave }\end{array}$ & $\begin{array}{l}\text { Approxomate sine } \\
\text { wave }\end{array}$ \\
\hline $\begin{array}{l}\text { In reference to } \alpha-\beta \text { axes } \\
\text { consists of ripple }\end{array}$ & $\begin{array}{l}\text { Approxomate sine } \\
\text { wave }\end{array}$ \\
\hline $\begin{array}{l}\text { 6.Stator voltages } \\
\text { In reference to } \alpha \text { - } \beta \text { axes }\end{array}$ & $\begin{array}{l}\text { Not sine wave and } \\
\text { consists of ripple }\end{array}$ & $\begin{array}{l}\text { Approxomate sine } \\
\text { wave }\end{array}$ \\
\hline $\begin{array}{l}\text { 7.Torque and speed } \\
\text { response of induction } \\
\text { motor }\end{array}$ & $\begin{array}{l}\text { Sluggish and slow } \\
\text { response }\end{array}$ & Response is fast \\
\hline
\end{tabular}

\section{CONCLUSIONS}

Induction motor torque response can be controlled effectively by Direct Torque control method. The inverter current is controlled by SVPWM stratergy. This method eliminates the co-ordinate transformation done in vector control method which consumes more computing time. The torque and speed response time is reduced. With DTC Power loss in current source inverter is reduced. Stator and rotor flux estimated are sinusoidal in nature and it has a circular trajectory. The stator currents and voltages is indirectly controlled by DTC and are approximately sinusoidal.

\section{REFERENCES}

1. I.Takahashi and T.Noguchi, “A New Quick-Response and High-Efficiency Control Strategy of an Induction Motor" , IEEE Transaction on Industry Applications, Vol. 22, pp. 820-827,1986.

2. M.Depenbrok, "Direct Self-Control (DSC) of Inverter-Fed Induction Machine, IEEE Trans. on Powe Electronics” Vol.4, , pp. 420-429.1988.

3. P.Tiitinen, P.Pohjalainen and J.Lalu," The next generation motor control method: Direct Torque Control (DTC)", European Power Electronics Journal, Vol.5, , pp. 14-18, 1995.

4. G.Buja, D.Casadei and G.Serra, "Direct Stator Flux and Torque Control of an Induction Motor: Theoretical Analysis and Experimental

5. Results", The IEEE International Conference on Industrial Electronics IECON '98, Bologna, Italy.1998.

6. D.Casadei, G.Serra, A.Tani, L.Zarri and F.Profumo, "Performance Analysis of a Speed-Sensorless Induction motor Drive Based on a ConstantSwitching-Frequency DTC Scheme”, IEEE Transactions on Industrial Applications, Vol.39, pp. 476-484. 2003.

7. Bimal K.bose, "Modern Power Electronics and AC Drives", Delhi ,India: Pearson Education(Singapore) Pvt. Ltd., 2003.

8. Abdul Rahiman Beig and V.T.Ranagnathan, "A Novel CSI-Fed Induction Motor Drive" , IEEE Trans . on Power Electronics, Vol.21,No. 4, pp 1073-1082, July 2006

9. Do-Hyun Jang and Duck-Yong Yoon " Space-Vector PWM Technique for two-phase Inverter- Fed Two-Phase Induction Motors, IEEE

10. Trans. on Industry Applications ", Vol. 39, No.2, March/April 2003. 


\section{International Journal of Advanced Research in Electrical, Electronics and Instrumentation Engineering}

\section{(An ISO 3297: 2007 Certified Organization)}

\section{Vol. 3, Issue 9, September 2014}

11. Aleksandar Nikolic and Borislav Jeftenic, "Different Methods for Direct Torque Control of Induction Motor fed From Current Source Inverter, WSEAS Trans. on Circuits and Systems", Issue 7, Vol. 7, July 2008

12. Farouk M. Abdel-kader, A. EL-Saadawi, A. E. KALAS, Osama M.EL-baksawi” Study In Direct Torque Control of Induction Motor By Using Space Vector Modulation", IEEE Trans . on Power Electronics ,2008

13. D.Casadei, G.Serra, A.Tani, L.Zarri and F.Profumo, "Performance Analysis of a Speed-Sensor less Induction Motor Drive Based on a Constant-Switching-Frequency DTC Scheme”, IEEE Transactions on Industrial Applications, Vol.39, , pp. 476-484. 2003.

14. Aleksandar Nikolic and Borislav Jefienic,"Speed Sensorless Direct Torque Control Implementation in a Current Source Inverter Fed

15. Induction Motor Drive”, 35th Annual IEEE Power Electronics Specialists Conference, 2004,PESC 2004, Aachen, Germany, June 2004.

16. Yen-Shin Lai, Jain-Ho Chen, "A New Approach to Direct Torque Control of Induction Motor Drives for Constant Inverter Switching

17. Frequency and Torque Ripple Reduction", IEEE Transaction on energy Conversion, vol.16, No.3, Sep 2001.

18. Cristian Lascu, Ion Boldea, Frede Blaabjerg, "A Modified Direct Torque Control for Induction Motor Sensorless Drive", IEEE

19. Transaction on en ergy application, Vol. 36, No.1, Jan/Feb 2000.

20. Lamia Youb and Aurelian Craciunescu, "A Comparison of Various Strategies for Direct Torque Control of Induction Motors, IEEE Transaction 